\title{
Les langues au cœur de nouveaux défis
}

\section{Gilbert Dalgalian}

\section{OpenEdition}

\section{Journals}

Édition électronique

URL : http://journals.openedition.org/esp/4074

DOI : $10.4000 /$ esp.4074

ISSN : 2532-0319

\section{Éditeur}

Centre d'Information sur l'Éducation Bilingue et Plurilingue

\section{Édition imprimée}

Date de publication : 1 juin 2019

Pagination : 83-85

ISSN : 1127-266X

\section{Référence électronique}

Gilbert Dalgalian, «Les langues au cœur de nouveaux défis », Éducation et sociétés plurilingues [En ligne], 46 | 2019, mis en ligne le 01 février 2021, consulté le 01 mars 2021. URL : http:// journals.openedition.org/esp/4074 ; DOI : https://doi.org/10.4000/esp.4074

Ce document a été généré automatiquement le 1 mars 2021

(c) CIEBP 


\title{
Les langues au cœur de nouveaux défis
}

\author{
Gilbert Dalgalian
}

1 Le monde est en pleine mutation. À l'explosion démographique viennent s'ajouter de multiples facteurs poussant des populations de plus en plus nombreuses à chercher leur survie dans l'émigration.

2 Des changements sociaux et politiques de grande ampleur se dessinent partout déstabilisant les sociétés : en Amérique latine, en Afrique, en Asie du Sud-est et, bien entendu, au Proche-Orient où les guerres sont une raison de plus pour fuir vers un hypothétique pays d'accueil.

3 Pourquoi évoquer ces bouleversements dans notre revue Éducation et sociétés plurilingues?

4 Parce que la façon de résoudre les problèmes de langues sera révélatrice du respect manifesté envers ces populations déplacées et fragiles. Le traitement réservé aux migrants se traduit d'abord et surtout dans le regard que l'on porte sur leurs langues et leurs cultures.

5 Voyons plus en profondeur. Les États européens ont - à des degrés divers - mis en œuvre des politiques de verrouillage des frontières et de forte limitation des entrées sur leurs territoires.

6 Pourtant quelle est la réalité des pays d'Europe et d'Amérique du Nord? Partout l'histoire s'est construite sur les migrations et le métissage. Partout les sociétés sont depuis longtemps multilingues avec un nombre important de citoyens plurilingues. Même si ce multilinguisme est rarement reconnu et encore moins officialisé. Seule la Suisse est une exception exemplaire.

7 Les sociétés contemporaines - d'Europe et d'Amérique - sont clairement des sociétés arc-en-ciel. C'est cela qui fait leur richesse à tous les niveaux: artistique, littéraire, scientifique, humain. Cette tendance ancienne aux migrations et aux métissages ira se renforçant avec les nouvelles menaces sur la planète, sur la santé, sur l'alimentation, sur la paix civile et la démocratie. Donc sur la vie et la survie des peuples. 
Désormais il ne suffira pas de vouloir accueillir. Il ne suffira pas d'ouvrir les frontières. Encore faut-il à la fois ne pas donner prise aux réactions ethnocentriques et xénophobes et concevoir la meilleure harmonie possible entre migrants et populations des pays d'accueil. Il faudra définir les conditions du respect mutuel, fondement de toute harmonie.

Dans cet effort la politique des langues sera un test - majeur - du respect mutuel. Plusieurs États ont légiféré l'obligation d'apprendre la langue du pays d'accueil. C'est une nécessité. Mais ce n'est que la moitié du contrat de confiance. Il faut y ajouter le droit au bilinguisme pour les nouveaux arrivants. Y compris à une éducation bilingue lorsque les effectifs d'élèves le permettent.

10 Ce droit à une éducation bilingue est loin d'être acquis. Il s'inscrit à contresens des traditions centralisatrices presque partout. En France notamment, il entre en conflit avec une idéologie du monolinguisme qui explique le retard des filières bilingues au bénéfice des langues régionales.

11 Car non seulement l'éducation bilingue est rarement offerte aux enfants de migrants, mais elle n'a, en outre, été accordée qu'au compte-gouttes aux nationaux eux-mêmes qui désiraient transmettre à leurs enfants le breton, l'occitan, le basque, le corse, l'alsacien et l'allemand, ailleurs le créole. Il s'agira bien évidemment d'un aggiornamento idéologique.

12 Pourtant dans la mise en œuvre d'une éducation bilingue, une erreur serait de la réserver aux seuls enfants d'un groupe ethnique particulier. Ce serait construire des ghettos scolaires ethnocentrés.

13 Le respect mutuel se traduit certes par l'apprentissage de la langue du pays d'accueil, mais aussi et de façon simultanée, par l'ouverture de filières bilingues à tous les enfants du pays d'accueil sans distinction d'origine, quand les familles le souhaitent.

14 Seul ce test du respect mutuel, clairement institutionnalisé dans l'éducation, permettra aux nouveaux citoyens issus de l'immigration de percevoir qu'ils sont accueillis et d'adhérer aux lois du pays d'accueil: laïcité, respect de la femme, respect des autres ethnies et religions, ainsi que des principes démocratiques.

15 L'harmonie a ses contraintes. Les ignorer serait aveuglement et source de conflits. Nos sociétés doivent s'adapter pour répondre avec humanisme aux nouveaux défis.

\section{RÉSUMÉS}

Il mondo è in piena trasformazione. All'esplosione demografica si aggiungono molteplici fattori che spingono popolazioni sempre più numerose a cercare di sopravvivere grazie all'emigrazione. Il modo di risolvere i problemi legati alle lingue sarà rivelatore del rispetto manifestato nei confronti di queste popolazioni in movimento e fragili. Il trattamento riservato ai migranti si traduce in primo luogo e soprattutto nel modo di vedere le loro lingue e le loro culture.

The world continues to change. A multiplicity of factors pushes entire populations to seek their survival by emigrating, compounding the present-day demographic explosion. The ways we solve 
linguistic problems reveal if and how much we respect those fragile displaced persons. The manners we treat them is above all clear in the consideration we show for their languages and cultures.

INDEX

Keywords : demographics, wecloming migants, survival, respect, languages in migration Parole chiave : demografia, accoglienza dei migranti, sopravvivenza, rispetto, lingue d'emigrazione

\section{AUTEUR}

\section{GILBERT DALGALIAN}

Linguiste 